\title{
Reconceptualizing Cultural Narratives of Mature Women's Sexuality in the Viagra Era
}

\author{
Tiina Vares, Annie Potts, Nicola Gavey, Victoria M. Grace
}

\begin{abstract}
To date, women's accounts of sexuality and sexual changes in mid-later life have been neglected by both feminists and gerontologists. In addition, women's responses to male partners' use of sexuopharmaceuticals such as Viagra (as a "solution" for erectile changes affecting older men) have received little attention. This paper reports on a New Zealand-based research which involved in-depth interview with 27 women, in mid-later life, who were partners of men that used Viagra. We analyse the accounts of 15 women who discussed changes/'improvements' in their sexuality over the life course and with their partners' use of Viagra. Central to the accounts we present is an articulation of an active and desirous female sexuality in mid-later life. These narratives, we suggest, not only challenge the culture stereotype of mid-later life sexual decline for women, but also open up new spaces for feminist theorizing of heterosexuality and changing experiences of heterosexuality across the course.
\end{abstract}

Keywords: Women's sexuality; Aging; Heterosexuality; Gender; Viagra 


\section{Introduction}

The western cultural narrative of "midlife decline" identified by Gullette (1997) applies to sexuality (and a variety of changes associated with ageing) and to both women and men. According to this narrative, sexuality diminishes with age and this decline is framed as an inevitable and "negative" outcome of ageing (Gullette, 1997). However, in recent years, the medicalization of male sexuality (in particular, the increasing attention given to 'erectile dysfunction' (ED) as a condition affecting older men) and the advent of sexuopharmaceuticals such as Viagra to combat ED, have challenged the sexual decline narrative for men (and to some degree for women). Since the advent of the 'Viagra era' (1998) Marshall and Katz (2002) have identified the creation of a new imperative in western societies to maintain "busy bodies" in older age. This is especially evident, they argue, in the realm of sexuality, where it is now assumed that the ability to remain vigorously active across the lifespan is a measure of overall health, fitness and productivity (Marshall \& Katz, 2002). Furthermore, 'lifelong sexual function', for men, is defined as the ability to maintain an erection for the purpose of completing male orgasm through penile-vaginal penetration (Marshall, 2002; Marshall and Katz, 2002; Katz \& Marshall, 2003).

We would like to suggest that these changes associated with the medicalization of male sexuality have facilitated the emergence of an 'anti-decline' narrative for men, in which decline is no longer viewed as necessary or 'normal' (see Potts et al. 2006). Viagra and other sexuopharmaceuticals have enabled some $\operatorname{men}^{1}$ to experience the restoration of erections and thus the possibility of 'sex for life'. In effect, the pathologization of erectile difficulties/'decline' has promoted the continuation of 'potent' and 'youthful' sexuality, particularly penile-vaginal penetration. The anti-decline narrative has therefore worked to disrupt the certainty and inevitability of 'natural' male sexual decline with ageing. However, this raises some crucial questions with respect to the female partners of men, for as Tiefer (1995) argues, women also occupy an essential place in the discourse of medicalization (the need for vaginal "penetration" is, after all, the justification for the entire enterprise). Yet women are only present in terms of universalized vaginal needs - their actual desires and opinions are conveniently invisible, neglected, or denied. How do women negotiate between the decline narratives 
for women and men, the increasingly prevalent anti-decline narrative for men, and the emergent cultural imperative to remain sexually active?

We address this question in our exploration of some mid-later life women's accounts of sexuality and changes in sexuality over the life course. The women draw on, and negotiate with, a variety of narratives on sexuality and ageing. Rather than employ a decline narrative, many describe their sexuality as they age as "getting better all the time". For some women, changes with ageing and experience are associated with an expansion of non-coital sexual activities. For others, penile-vaginal penetration takes on more importance and is presented as integral to their sexual pleasure and satisfaction.

We draw on the accounts of 27 women, aged between 33 and 68 years (with a mean age of 53), whose partners used Viagra. The interviews were conducted as part of an independent national study on the social impact of Viagra (funded by the Health Research Council of New Zealand). We noted a great diversity of responses and experiences among participants. Some participants, for example, employed a decline narrative in which ageing was associated with a decline in sexual interest, desire and activity. Several women felt people's sexuality and sex life changed 'naturally' with age, for example, a decrease in the frequency of sex. This was not, however, viewed as a negative consequence of getting older, considered a 'problem' or seen as 'dysfunctional'. For these women their partner's use of Viagra meant that the reintroduction of penile-vaginal penetration into their lives was not always what they wanted (see Potts et al., 2003).

Nonetheless, other narratives were identified in which participants talked of experiencing increased sexual desire and pleasure as they aged and some stressed the importance of penetrative (penile-vaginal) sex in satisfying their sexual desires. In this paper we focus on the accounts of 15 women $^{2}$ who talked of such changes or 'improvements' in their sexuality as they aged. Central to the accounts we present is an articulation of an active and desirous female sexuality in mid-later life. What is striking in much of the talk examined in this paper is the way in which many norms associated with 'heterosex' or normative heterosexuality are challenged, for example; the privileging of male sexual pleasure through vaginal penetration, the construction of sexual control and knowledge as 'male', and the notion of an uncontrollable 'male sex 
drive' (see Segal, 1994; Jackson, 1995; Potts, 2002). Many participants present themselves as "red-blooded", active sexual agents who find sexual activity, often including penile-vaginal penetration, both desirable and pleasurable.

Many feminists have indicated that the feminist critiques of heterosexuality in the 1980s (or the so-called 'sex wars') have made it somewhat problematic to talk about sexual pleasure in heterosexual relationships. Segal (1994), for example, notes that since the 'sex wars' the specific details of heterosexual women's desires and practical pleasures have been discussed less and less in feminist theorizing. This is, she suggests, in part because heterosexuality has become increasingly identified with heterosexism. Nonetheless, Segal and others have insisted on acknowledging and exploring women's pleasures of heterosexual sex (without framing these women as "victims of patriarchy"). Segal (1997), for example, has been a "defender of heterosexual eroticism" (Jackson, 2003:74), while also being aware of inequalities in heterosexual relationships, of sexual coercion and sexual violence. Segal argues that we need to rethink the very idea of heterosexuality, and the associated symbolism that sex is something men do and women have done to them, by talking more, not less, about the diversity of heterosexual experiences and bodily contacts (1997:82). For both Segal and Smart (1996), a focus on women's sexual agency should be part of the move to displace the heterosexual order. This means that whilst acknowledging and acting against the harms of heterosexuality, we also need to hear what women have to say about its pleasures (Smart, 1996:238). In particular, we would add, we need to hear the voices of women in mid-later life who have been neglected by both feminists and gerontologists (Matthias et al., 1997; Gott \& Hinchliff, 2003). We argue that attending to the diversity and fluidity of women's sexuality, particularly in mid-later life, is a crucial component in unpicking the normative status of heterosexuality. We agree with Jackson that it is unhelpful to think that the dominant meanings of heterosexual penetration are fixed, unassailable and beyond the reach of a variety of feminist reconceptualizations (2003:74).

\section{Methodology}

This study draws on transcript material from individual interviews with women whose partners used Viagra. In early 2001, advertisements calling for participants for a 
national study on the social impact of Viagra featured on radio, in local newspapers and popular magazines throughout New Zealand. In response to these advertisements 27 women volunteered to take part in a study to talk about their perspectives and experiences as partners of men who used Viagra (thirty-three men also took part in a complementary study on men's experiences of using Viagra). Interviews took place at different locations throughout the country between April and September 2001. Participants chose to be interviewed in their homes or at the local university by a member of the research team. Interviews lasted between 1-2 hours and followed a semistructured format ${ }^{3}$, focusing on women's perspectives and experiences of Viagra use by male partners. Participants were also encouraged to talk about other related issues of relevance to them and their specific relationships. Interviews generally began with women being asked to relay their own 'story' of Viagra use in their relationship, and then moved on to unpack specific issues and topics including: the impact of sexual changes or difficulties on relationships; the physical effects for women of Viagra use by a male partner and their views on the implications of greater attention to sexual difficulties (and the various treatment options) for our understandings about sexuality and older people. All interviews were audio-taped and transcribed in full. Repeated close readings of the transcripts were conducted in order to identify key themes related to the experience of sexual difficulties within relationships, the use of Viagra or similar medical interventions, and women's perspectives on sexuality and ageing.

In this paper we conduct a thematic analysis, informed by feminist theory, of narratives of changes or improvements in sexuality over the life course that were presented by some women. To begin, we explore the ways in which some women present their sexuality in mid-later life as improving with age (particularly in relation to increased knowledge of their own bodies, sexual desires and preferences for coital and non-coital activities). We then focus on those accounts in which penile-vaginal penetration has become increasingly important for participants (or 'his Viagra for her'), and finally consider some participants' descriptions of differing 'sexual appetites' between partners in which they desire more sexual activity than their male partners.

When presenting extracts from interviews in this report, we have omitted word repetitions and all speech hesitations (i.e., all terms such as 'um' and 'ah'). The presence of three consecutive dots [...] indicates a portion of speech has been cut. 
Square brackets are used around words and/or phrases to indicate where wording has been changed, either for the sake of clarity or to avoid identifying places or people. When the text inside the square brackets is in italics this indicates interviewer notes. Pseudonyms are used for all participants and the number in brackets following the pseudonym indicates the age of the participant.

\section{"Improves with age": Changing sexual pleasures and practices over the life course}

A number of participants described their continued and pleasurable sexual activity in mid-later life. For some, this was done by first orienting to the dominant "asexual older people storyline" (Jones, 2002) and the "decline narrative" (Gullette, 1997) in which people lose both interest in, and the ability to have, sex as they age. It could be argued that these participants need to do the discursive work of establishing the "truth" of their account, which is not the case for those employing the dominant decline narrative (Jones, 2002:126). For example:

Marion (56): [...] What they don't know is that there's a big secret out there [laughs] which is older people are [having sex]. I mean we're the first wave of the baby boomers. What are we going to do, sit around knitting? Nobody knows how to knit! [laughs]

June (57): I'm getting older but, oh I still enjoy it. [...] I still enjoy sex even though I'm 57 years old. I wouldn't like to be doing it twenty-four hours a day, but you know a couple of times - three times a week is very, very nice.

Paula (60): I know that older people are not supposed to [have sex] as though [we've] grown out of it, which is just rubbish. [...] As far as the need for it is concerned or the fact that we still 'do it', as the young say, our age has not made any difference $[\ldots]$.

These three women introduce their accounts by acknowledging the prominence of the narrative that older people "are not supposed" to have sex. Marion, for example, frames the fact that she and other older people are having, and enjoying, sex as a "big secret". Countering the asexual later life narrative is thus integral to the telling of their experiences. 
It is significant that Marion and others (below) position their different understandings of sexuality in a socio-historic context. This acknowledges that sexual experiences and practices change through time and with changing social and cultural conditions. These women grew up in very different sociocultural contexts to those of their mothers and grandmothers, that is, during the so-called 'sexual revolution' and witnessing the introduction of the contraceptive pill. Furthermore, when many of the participants were entering early adulthood in the 1960s and 1970s there were 'new' representations of younger women as sexually active, rather than simply passive, and notions of what was considered appropriate sexual behaviour also shifted.

It is therefore interesting that Marion and others position sexuality in mid-later life as "better than" sexual relations when they were younger (that is, growing up in the 1960s and 1970s). In the following extracts, as participants discuss sexual changes over the life course, the more dominant narratives of 'sexual decline as one ages' and 'sexual pleasure as the domain of the young' are disrupted in various ways and to varying degrees:

Linda (50): In [my] twenties and probably thirties to a degree I remember it as being more of just having a bonk type of thing and not the pleasurable aspects of it so much. I think now it's more of the caring type of relationship that I'm in and I think it's more now knowing my own body so well. The relationship that [my partner] and I have [is] - I was going to say experimental which sounds odd at our age - but it's one of those things that we just enjoy each other and each other's company. If I want to try something just for the hell of it then I've got the confidence to do that, whereas I certainly wouldn't have tried that in my twenties or thirties.

[...] [There's been a] change in my own attitude. I guess maybe it's an age group thing as well. To me, [sex] wasn't done so much for females, it was done for the male, whereas now I'm quite happy to do it for myself. [That might] sound a slightly selfish attitude but I think that's the attitude males used to have then.

Jan (56): [...] [My partner] satisfies me more now, [I] have more orgasms now than I ever have. I keep saying this is good. The older I get the better it gets. [...] [When I was younger] it was more the bloke's role to lead, whereas now I more often than not lead.

Marion (56): I had a rotten sex life basically in my younger days. I think it was because I grew up in a time when the pill hadn't been invented, and the big fear of 
life was to get pregnant when you weren't supposed to. And I think that always remained a certain inhibiting factor.

[...] I think, particularly when I was young, it was like the search for the extremely elusive orgasm. I knew it existed out there but it didn't happen for many years. And it's only now that I have regular orgasms.

Sarah (66): I think I'm probably more interested in sex now than I used to be, but at the same time a lack of intercourse doesn't worry me. It was many years before I discovered masturbation.

Julie (60): [My sexuality has changed] for the better. I was never satisfied with this sort of wham-bam-thank-you-mam [sex] and I do remember reading various books about what was happening. Why wasn't I having, you know, why weren't clouds bursting and angels coming out with trumpets? And then I thought - I know - because I'm not being looked after, there's no foreplay.

Allison (43): [...] I think I was a late developer. I've really enjoyed sex much better as I've got older, definitely. I think I've learnt about my own body. I think I never had an orgasm before I was probably 30. Terrible thing to say! And when I discovered that and I suppose it's becoming comfortable with one partner, which is really nice and trying different things. I think probably masturbating too. So yeah I suppose a number of things really and becoming more relaxed with one person.

These extracts illustrate what Gullette (1998) calls a "progress" narrative in which participants describe their present sexuality as better than in their youth. The reasons given for improvements in sexual relationships and pleasures range from the introduction of contraception in the form of the pill, increasing knowledge of one's body and the ability to get pleasure from it (both alone and partnered), feeling more comfortable with partners, and the changing sexual practices of male partners.

Jan and Linda (above) refer to their early male sexual partners as "selfish", and "leading" in sex. Sex was primarily "for men", not for women. It is, therefore, not surprising that many participants reported having little sexual pleasure with respect to orgasms in their early sexual relationships. Allison didn't have an orgasm until she was 30 and Marion until her early 50s. Some of the men that participated in our wider study also talked of being "selfish" in their early sexual relationships and being primarily focused on male orgasm through penetration (see Potts et al., 2006). However, as they age many women (and men) challenge sexual practices which frame men as active and 
initiating, and women as passive and responsive. The women talk of having more confidence and leading or initiating sexual contact, as well as being able to pleasure themselves. The changes in sexuality the women articulate offer challenges to dominant sexual scripts which privilege heterosexual intercourse, specifically the 'coital' imperative or the idea that 'real' sex equals penis-in-vagina penetration (Jackson, 1984) and the construction of sexual control and knowledge as 'male'(see Segal, 1994; Jackson, 1995; Potts 2002.) However, what is more significant is the disruption offered to age-related sexual scripts for women.

For some participants, greater interest in sex was not affected by male partners' erectile difficulties. In fact, in some cases, erectile difficulties facilitated "positive" changes which involved a greater variety of (non-coital) sexual activities. For example, Sarah (66) talks of being more interested in sex, yet not really being concerned with a lack of intercourse. Suzanne also refers to her sexuality "improving" with age and, in particular, as a result of changes in sexual relations associated with her partner's erectile difficulties:

Suzanne (52): I think as a result of [erectile difficulties and no success with Viagra], because we've had to have more variety, talk about things, and that has improved my attitude. [...] I wasn't very keen before, I'm more keen now than I was before.

Viagra has not worked for Jan's (56) partner, however, she describes pleasurable sexual relations and talks of sex getting better with age: "we get just as much pleasure out of cuddling and we also have a lot of foreplay and stuff'. Sexual experimentation and wider sexual repertoires were reported by a number of participants. Thus, for many participants sexuality involves non-coital activities and mutually enjoyable sexual activities. This highlights some of the potential problems with previous predominantly quantitative research in the area of ageing and sexuality which has tended to frame sexual activity as heterosexual penile-vaginal intercourse and focused on the frequency of coital sex (see for example, Diokno et al. 1997; Bergstrom-Walan \& Nielsen, 1990). The emphasis in former studies on (frequency of) coitus limits the development of more encompassing understandings of what constitutes sexual activity for those in later life and fails to capture the different meanings associated with sexual experience for people in mid-later life. Participants' narratives above indicate broader understandings of what 
constitutes sexuality, in particular, the way in which sexuality is not necessarily equated with penile-vaginal penetration. In other words, sexuality encompasses sense of self, interaction with others and many levels of expression and affection (Roughan et al., 1993: 87). Such accounts can help to destabilise the conventional restrictive narratives of what constitutes heterosexuality, particularly in mid-later life.

\section{His Viagra for her}

While it is important to challenge heteronormative constructions of sexuality which focus on penile-vaginal penetration, we argue that it is also important to attend to some women's accounts of sexuality that privilege penetrative sex and its pleasures. As stated earlier we suggest that attending to women's pleasures relating to coital sex is also important for reconceptualizing heterosex. Perhaps, as Segal (1997) argues, one way we can rethink heterosexuality is by disrupting the cultural symbolism of masculinity with activity and femininity as passivity through focusing on narratives in which women actively seek, initiate and enjoy penile-vaginal penetration. Perhaps some versions of heterosex are about more than simply endorsing male dominance and privilege through sex - hence, reminding us that we need to keep in mind the plurality and diversity of heterosexualities. And perhaps, as Smart (1996) suggests, by disengaging penetration from heterosexuality and re-coding it as more sexually ambivalent, we may be able to move in the direction of a "post-heterosexual" desire. We offer these ideas as possible ways to think about/through the material we now present, not as definitive solutions to the thorny issue of women's heterosexual desire and pleasure. In this section, we explore the accounts of those women for whom the erect penis and penile-vaginal penetration are framed as integral to their sexual satisfaction in mid-later life.

In the previous extracts participants challenged the decline narrative for older people more generally, and for women in particular. Below, participants' use of the decline narrative is more explicitly gendered - women's sexuality is seen to improve with age but men's sexuality is presented as declining with age. Furthermore, while women's sexual change is predominantly understood in sociocultural terms (for example, greater knowledge of, and comfort with, their bodies), men's sexual change is presented in terms of physical decline. While drawing on the cultural ageing/sexual decline 
narrative, this framing is also potentially informed by the proliferation of discourses surrounding the medicalization of 'erectile dysfunction' (ED) which present ED as a physical problem. ${ }^{4}$ Up until recently, the medical establishment considered that erectile disorder was primarily psychological in origin (Bivalacqua et al., 2000), however, today it is not uncommon to read that "at least $90 \%$ of all male sexual dysfunctions have an organic or medical cause" (Bass, 2000: 339). The representation of erectile difficulties in terms of physical decline also means that sexuopharmaceuticals which offer to 'fix' such difficulties, such as Viagra, become desirable because they benefit not only men, but also women.

Rather than seeing male erectile difficulties as part of a 'progress' narrative in which non-penetrative and alternative sexual activities can be pursued (see Potts et al., 2004), the accounts of these participants utilise both a decline narrative (in which sexual decline is 'natural' and inevitable) and an anti-decline narrative which emphasizes restoration and problematizes decline. Many of the participants talked of how an erect penis, penile-vaginal penetration, and orgasms resulting from coitus were central to their sexual relationships and pleasures. Viagra was thus seen as enabling the continuation of a successful and pleasurable sexual relationship. ${ }^{5}$ For some women this takes on greater significance because they only started experiencing orgasms in their 30 s, 40s or 50s. Karyn, for example, has always enjoyed sex but since forty years of age has "woken up to the possibility of what's possible", in terms of the pleasures of penile-vaginal penetration. Karyn has had 4 marriages and her sexual desires and pleasures have changed over that time:

Karyn (55): It's only in the last two [marriages] that I wanted penetrative sex [...] but I didn't feel like that before. [...] I like all the touching, all the stimulation, I want all that, but I also want his penis hard so if I want it in me I can have it in me for as long as I want.

The relative newness of the desire for, and pleasure from, penile-vaginal penetration and a 'hard penis' means that Karyn is less likely to accept erectile difficulties in a relationship. 
For some women, orgasm is achieved through penile-vaginal penetration with an erect penis. The Viagra-enhanced penis may therefore facilitate ("easier") orgasm for women:

Maria (50): I think it's physically easier to orgasm with [Viagra because] the penis is so much firmer, that you can feel it better. [Without Viagra] it's a bit like a damp sponge. When you try [with your vagina] to grip on this thing, it's a heck of an effort. But when the erection has Viagra as an element it's just firmer like a real erection.

Maria's description of trying to "grip" onto the penis is interesting in this context. Rather than position herself as being penetrated by a penis and thus more 'passive', Maria is 'active' in this process - she is the one who grips the penis and exerts effort in order to do so. This particular framing is potentially one way of rethinking heterosex by disrupting the cultural symbolism of masculinity/activity and femininity/passivity.

In addition to Viagra potentially assisting with the firmness of erections, it is also described as addressing the problem of erratic erections, or the unreliability of the nonViagra enhanced penis. For Marion, for example, Viagra-sex is more exciting because it prolongs the erection, which is important for her to have better sex. For Karyn, nonViagra-sex was also not as satisfying for her:

Karyn (55): [...] Because what I found was that his erection was not very strong and that sometimes it would be there and sometimes it wouldn't. With that kind of erraticness it wasn't good for me.

For Karyn, Viagra-aided erections thus give her some "control" in sex (see also Grace et al., 2006, in which some men who use Viagra also articulate a view that their taking Viagra is "for her" and the enhancement of her sexual enjoyment):

Karyn (55): If [my partner] has an erection, well I'm going to use it. I'm going to have some fun here. I want some control in this thing and if taking Viagra gives you that, it gives you the security and the knowledge that if you want to have a good sexual time with your partner you can and nothing's going to get in the way.

Normative understandings of heterosex traditionally positioned women as requiring penile penetration to reach orgasm. This is underpinned by the assumption that women are passive in this process (that is, men "give" women an orgasm, see Guilfoyle et al., 
1993). Although the participants' narratives focus on sexual pleasure from penilevaginal penetration, they do not present this as the only way of having sexual pleasure. Neither do they position themselves as 'passive' and dependent on male 'sexpertise' (Potts, 2002) to ensure their sexual satisfaction. Nonetheless, while penile-vaginal penetration is not the only way for women to achieve an orgasm, for Marion it is framed as the "best" way and the best orgasm:

Marion (56): [Orgasm is] the whole point of the exercise really, the exciting bit. If you don't get the exciting bit it's like having the cake but no icing. [...] Because whatever else we do it always ends up as penetrative sex for orgasmic purposes. That's how you get the best one.

Marion articulates both a 'coital imperative' (Gavey, McPhillips \& Braun, 1999) and an 'orgasmic imperative' (Potts, 2002) and the erect penis is vital to both. Furthermore, she indicates that it is the responsibility of the man to 'fix' any erectile problems. If he fails to do so, for Marion, this signals the end of the relationship: "either address it or get out of my bed" (Potts et al., 2003). Viagra then becomes the tool by which to fix the sexual relationship or, in fact, have a particular relationship:

Marion (56): If it wasn't for Viagra basically there wouldn't be the relationship. I'm not going to live with someone who doesn't have sex. [...]

Interviewer: So if your partner couldn't have an erection, have sex with you, then there wouldn't be a point to you being with him?

Marion (56): No.

Mary raised a similar issue with her partner in light of his "feeble" erections:

Mary (68): We've talked [about if he can't get and maintain erections] hypothetically and it's been very hypothetical. I said, 'if there was no sex between us, how do you expect me to behave? Now what loyalties do I owe you?'

For Marion and Mary a man needs to be able to achieve an erection in order to stay in the relationship. Karyn also expresses a desire for penile-vaginal penetration in a sexual relationship and evaluates her relationships on the basis of male erectile performance:

Karyn (55): For me to have an intense live-in relationship, [erections and penetrative sex] are part of the deal as far as I'm concerned, and if you can't 
perform well, I will review whether I'm going to be here. [...] I want [penetrative sex and foreplay] and it seems to me that [with] older men it's not possible to do that without some kind of assistance. It doesn't bother me that they need assistance. What does bother me is - if there was nothing that you could do about it, and if that was so, I think I'd be in a relationship with a younger man.

Karyn utilises the male sexual decline narrative in which decline is seen as inevitable for all 'older men'. However, this in itself is not problematic for her. The problem arises if nothing can be done to 'fix' this erectile decline. In pre-Viagra days, or if Viagra fails to work, a younger man is presented as the solution for meeting her sexual needs. In a similar manner, Marion sees Viagra as beneficial in "recycling" the "old" male partner:

Marion (56): You don't have to have a toy-boy. You don't have to bother about that. You just send your partner, the old one that really was fading into disuse, you just send him to the local GP and get a prescription. It's like recycling isn't it? You don't have to go and spend all that time and effort and money looking for a suitable stud to do the job.

Both Marion and Karyn address various changing sexual dynamics within relationships as male partners age. Pre-Viagra, a solution to male erectile/sexual decline was to discard the 'fading' male or rather the male with the 'fading' erection. However, Viagra now offers a recycling solution through pharmaceutical prosthesis that makes such a scenario unnecessary. This is an articulation of the (male) anti-decline narrative in which restoration and performance take centre stage. What is striking in these accounts is the articulation of these women's sexual desires, and various strategies to meet them. The active, desiring sexual agents represented here are not those usually associated with women and, in particular, women in mid-later life.

Karyn describes a sentiment shared by several women, that is, how her partner "takes Viagra for [her] ". It was also Karyn that suggested her partner get Viagra:

Karyn (55): I said to my new husband - why I'd like you to try Viagra, I actually told him, this is not my best sexual experience in my life with you, and I want it to be better. 
Most significantly, Viagra is presented by these women as enabling women's sexual pleasure, with little attention to male sexual pleasure and penetration (one of the norms of heterosex). In contrast to accounts of women's sexuality as "reactive and responsive", with "fears of appearing too demanding" (see, for example, Nicolson \& Burr's 2003, study of heterosexual women's sexual relationships, aged 19-60), the participants' accounts presented here construct their sexuality as active, initiating, demanding and not dependent on, or overly concerned with, their male partner's desires or pleasures. This reminds us that we need to attend to the diversity and fluidity of women's sexuality in our discussions and critiques of normative heterosexuality, and the possibilities such narratives offer in reconceptualizing women's sexuality, particularly mid-later life sexuality.

\section{A "good red-blooded female"}

"Libido mismatch" (Roughan at al., 1993:96) is a term used to refer to the differing sexual desires or appetites of sexual partners. Sexual desire is generally represented as a "basic, biological urge, drive or instinct which demands satisfaction ... in men the urge is usually considered to be much stronger than in women" (Jackson, 1987:72). Hollway (1984) has referred to this common understanding of men's 'natural' and 'normal' need for sex as part of the 'male sexual drive' discourse. In the male sexual drive discourse men are positioned as always ready, willing and able to have sexual relations. In contrast, women's sexual desire is represented as being less than that of men and, in particular, requiring arousal by men. Thus in general, "libido mismatch" is thought of in terms of a male partner desiring/needing more sexual relations that his female partner. In fact, a more desiring female partner has historically been pathologized and the spectre of 'nymphomania', or its more contemporary counterpart 'sex addiction', still hangs over 'sexually desiring' women (Groneman, 2000). Karyn, for example, acknowledges the prevalence of the discourse of 'sex addiction' by refuting that she is 'sex addicted' for desiring sexual relations:

Karyn (55): I'm not sex addicted because I can live without it but when I'm in a relationship with a man I want a good sex life. 
Potential ways of dealing with differing sexual appetites when men have erectile difficulties (hence, supposedly less desire, see Potts et al., 2004) and women have more sexual desire have been framed in quite gendered ways. For example, for women "there is the dilemma of gracefully accepting what seems inevitable or of risking rebuff and embarrassment by broaching a topic not previously discussed" (italics added) (Roughan et al., 1993:96). While this was written pre-Viagra, the idea that women should deny or ignore their sexual desires if they are greater than those of a male partner, remains prevalent. This also connects with the idea that a woman should protect a man's self-esteem and sense of masculinity if he experiences ED. In this context she is expected to not express her desire or need for sex.

Potts has argued that the embodiment of an alternative, more active female sexuality can occur with the destabilization of those discourses which privilege the so-called male sex drive and its associated imperatives (2002:45). We consider the following women's accounts of differing sexual appetites as potentially contributing to such a destabilization. In the previous section women indicated that Viagra is seen as restoring male sexual potency for the 'naturally' declining older man. Nonetheless, and most significantly, even with male use of Viagra (and restored potency) some women still desire more sexual relations than their male partners.

Lynne is 48 years of age and newly married to her partner. She describes her sexual drive as that of a "good red-blooded female". This is an interesting twist on the representation of men as 'red-blooded' - usually referring to 'normal' heterosexual male desire. In usurping this phrase, Lynne positions herself as actively desiring. She also uses this to describe having more sexual desire than her husband. This mismatch is presented as being problematic, yet Lynne neither 'gracefully accepts' this nor shows 'embarrassment' in confronting her partner:

Lynne (48): This is the expectation I'd have, we need to meet this, we need to maintain this, because otherwise it would make me irritated with him.

[...] Interviewer: Does it feel like you need [sex] or want [sex]?

Lynne (48): Yes to both. Some women don't but I do. Yeah I think it's such a neat part - and I was without it for eight years and it was horrible. It's a very, very important part of marriage, a vital part of marriage. Yeah, when you've had a good thing you want it again. 
Other cultural narratives of what constitutes appropriate sexual desire for women were also disrupted by participants. One such narrative is of women desiring more non-coital activity than men. Karyn, however, wants more penile-vaginal penetration than her partner, which "surprises" her:

Karyn (55): [...] He will be content sometimes if I'm really tired to just hold me and so on, but I want more than that, so that kind of surprises me.

Pauline also talks of her love of sex and that she is more adventurous than her husband. In this extract the stereotype of the woman who is always too tired for sex is undone:

Pauline (47): I'd never be too tired. That's not me. I'd never be too tired ever - I always want it.

Kath's higher sexual appetite has been an ongoing issue in her relationship, "our sex life has never been as plentiful as I might have hoped that it would be". Part of the problem in her current relationship is the more frequent and spontaneous sex she had with other partners. With her current partner, sex was something he marked for Saturday nights:

Kath (54): We had sex on the Saturday night or whatever. I used to try and put forward the idea of sort of keeping the pot boiling but he just didn't seem to have a clue what I meant. So we ended up with the sort of very regular, certain times set aside for sex which would have been fine for him but didn't work well for me.

While she refers to "definite differences in appetite", she also talks of adjusting to the situation as she doesn't regard having an affair as an option. In this example, the 'graceful acceptance' strategy is adopted. For Jane, however, an affair is seen as a useful option when a male partner fails to meet her sexual needs:

Jane (48): [...] We have a tacit understanding which is we don't talk about [my affairs]. He knows he's not meeting some of my needs.

Jane also talks about the way in which a woman who has affairs is perceived by friends:

Jane (48): I'm sure there are some of our friends that go, "oh that [Jane] she's a wicked woman", but I could say to them, “yeah, but my needs weren't met here". 
I mean if you can't buy cornflakes in one supermarket you're going to go to another one. I mean it's as simple as that, and that's what I'd love to say to them to shut them up because nobody understands what goes on in a relationship at all.

While Jane doesn't explicitly refer to the gender dynamics with respect to a woman, in contrast to a man, having an affair, we do, however, get a sense of this with the phrase "wicked woman". Although it is possible that Jane is seen as "wicked" because she has an affair, we suspect that in the context of the rest of the interview this relates more to the construction of women's sexuality as passive and responsive. Historically, women who exhibited more sexual desire and initiative in sexual matters than their partners raised fears of abnormality and deviance (for example, 'nymphomania') (Groneman, 2000:38). In particular, post-menopausal women who were sexually desirous and active were framed as 'unnatural' and pathological (Groneman, 2000:21). It is this context in which it is possible to locate Jane's actions as "wicked". In the contemporary scene, Groneman (2000) suggests, a man's 'sex drive' should always be greater than that of a woman, and this is even more so the case for post-menopausal women. A 'desiring' woman, like Jane, therefore offers a challenge to the norms of heterosex and particularly to understandings of ageing women's sexuality.

Marion also reported not "getting enough" sex. She will often say to her partner, "stop watching the television or the football or whatever and kindly prepare yourself'. Her desire for sex, which she attributes in part to using Hormone Replacement Therapy, remains greater than that of her partner:

Marion (56): Well I found that [HRT pills are] an aphrodisiac. Because of this extra dosage I'm having I'm actually quite keen to have sex far more than I get it. Well frankly I'd like sex sort of twice a day, every day, but he simply couldn't cope with it.

For Marion, HRT is given as one reason for her increased sexual desire. Nonetheless, her male partner (who uses Viagra) cannot "cope" with this. The use of the phrasing in which Marion wants more sex than she can get is interesting and would more usually be attributed to men rather than women. It alludes to the male sexual drive discourse in which women are positioned as less desiring and not 'driven' by sexual desire. Marion's use of this phrasing, as with much of the phrasing presented in this paper, 
disrupts the representation of women as sexually passive, responsive, and less sexually desiring than men.

Although there is still a deep ambivalence towards female sexual desire (Groneman, 2000), particularly for women in mid-later life, these accounts, we suggest, illustrate the embodiment of a more active, desiring female sexuality and the destabilization of discourses which privilege heteronormativity.

\section{Some concluding comments}

In the accounts we have presented many of the norms associated with heterosex are disrupted: in particular, the privileging of men's rather than women's sexual pleasure through penile-vaginal penetration, the construction of sexual control and knowledge as 'male', and the notion of men's 'sex drive' being 'naturally' stronger than women's. What is most significant is that this disruption comes in the talk of women in mid-later life, who are more commonly represented as being asexual or having little desire. These participants' accounts refer to increased sexual desire, activity and pleasure with ageing. Many women talked of shifting from a more disembodied passive sexuality in their youth, to an actively embodying feminine sexuality as they aged. In their youth, participants' bodies were more subordinated to male sexual pleasure. Now, in mid-later life they are presented as active in defining and achieving their sexual pleasure. It seems, therefore, that these participants' experiences of sexuality over the life course include those which conform to norms of heterosex and also those which disrupt or challenge them. For some participants, 'improvements' in sexuality include a greater variety of non-coital sexual activities. For others, penile-vaginal penetration is presented as a desired and pleasurable activity, in fact, as integral to sexual relations. This privileging results in participants utilising a variety of strategies to deal with partners' changing erectile capacities (which are presented as 'naturally' declining with age). As these women desire (and in some cases, insist on) firm and enduring erections, Viagra is seen as offering a solution to 'fading' male sexuality/erections. In fact, Viagra is represented as central to maintenance of pleasurable sexual relations for some women. In some participants' talk 'sexual control' is constructed as 'female' and Viagra is framed as enabling women to have more control in sexual relations in terms of getting the type of erection (hard and lasting) and sex (sometimes penetrative) they 
desire. Furthermore, these participants present themselves as active and (often) more desiring than male partners. It is, however, also important to acknowledge that for other women their male partner's use of Viagra produced changes in their sexual relationship which were not welcome, for example, the re-establishment of frequent coital sex (or any sex) (see Potts et al., 2003).

These women's accounts of sexuality in mid-later life remind us that at the level of heterosexual practice and experience, heterosexuality is not monolithic (Jackson, 2003:75). In fact, the sexual practices and experiences of the participants have changed significantly over the course of their lives. In these narratives of sexuality in mid-later life women's sexual pleasures are legitimated, and women's sexual knowledge (for example, of their bodies and pleasures) is acknowledged. We would like to suggest that the reframing of heterosexual, penile-vaginal penetration discussed in this paper, opens up new possibilities and spaces for feminist theorizing, explorations of heterosexuality, and changing experiences of heterosexuality across the life course.

\section{Acknowledgments}

This research was made possible by a Health Research Council of New Zealand project grant. We are immensely grateful to the women who volunteered to take part in this study. Thanks too to the transcribers, Roxane Vosper and Sharon McFarlane. 


\section{Notes}

\footnotetext{
${ }^{1}$ A recent UK survey indicated that $56 \%$ of men with erectile dysfunction said that they had stopped taking treatment in the past, claiming that either it did not work or only worked inconsistently (SCRIP World Pharmaceutical News, 21 April 2004, PJB Publication Ltd.).

2 The 15 women were aged between 43 and 68 years of age. 7 women had been married for many years, 2 were newly married (although had been married before), 4 were in new relationships and 2 were in long-term relationships (although not married).

${ }^{3}$ General discussion guide:

Exploration of:

The physical implications for sexual partners of men who use prosexual drugs such as Viagra (and/or other medical treatments)

The psychological impact of sexual difficulties and their medical treatments

The impact of prosexual drug use - and the existence of sexual difficulties - on sexual relationships or sexual encounters; in particular, asking about issues such as consensual sex, coercion within sexual encounters, safer sex practice

The impact of prosexual drug use on relationships in general

Where relevant/appropriate:

Implications for understandings of sexuality and older people.

Note: we asked the women to tell their 'Viagra story' and encouraged them to talk about specific issues, that is, we did not have specific questions for them to answer.

${ }^{4}$ We are also mindful of the inevitable development of drugs like Viagra for women, and the ways in which some drugs (aimed, in the main, at enhancing women's capacity for orgasm) may change the landscape of heterosexual relationships yet again (as did 'the pill' and Viagra).

${ }^{5}$ Perhaps as older women articulate a position of desiring penile-vaginal penetration, this further contributes to amplifying the conditions for the medicalization of male sexuality when the 'organ' can't 'perform'. This arguably intensifies the male desire for Viagra, that is, for a sexuopharmaceutical intervention which is desired so their 'performance' is better 'for her'.
} 


\section{References}

Bass, B. A. 2001. "The Sexual Performance Perfection Industry and the Medicalization of Male Sexuality". The Family Journal 9 (3): 337-340.

Bivalacqua, T., H. C. Champion, W. J. G. Hellstrom, and P. J. Kadowitz. 2000. "Pharmacotherapy for Erectile Dysfunction". TiPS 21: 484-489.

Bergstrom-Walan, M., and H. Nielsen. 1990. "Sexual Expression among 60-80 year Old Men and Women: A Sample from Stockholm, Sweden". The Journal of Sex Research 27 (2): 289-295.

Diokno A., M. Brown, and A. R. Herzog. 1997. "Sexual Function in the Elderly". Archive of Internal Medicine 150: 97-200.

Gavey, N., K. McPhillips, and V. Braun. 1999. "Interruptus Coitus: Heterosexuals Accounting for Intercourse". Sexualities 2 (1): 35-68.

Gilfoyle, J., J. Wilson, and Brown. 1992. "Sex, Organs and Audiotape: A Discourse Analytic Approach to Talking about Heterosexual Sex and Relationships". Feminism and Psychology 2 (2): 209-230.

Gott C. M., and S. Hinchliff. 2003. "How Important is Sex in Later Life? The Views of Older People". Social Science and Medicine 56: 1617-1628.

Grace, V. M., A. Potts, A., N. Gavey, and T. Vares (2006) "The Discursive Condition of Viagra". Sexualities 9 (3): 295-314.

Groneman, C. 2000. Nymphomania: A History. New York: W. W. Norton.

Gullette, M. M. 1997. Declining to Decline: Cultural Combat and the Politics of the Midlife. Charlottesville and London: University Press of Virginia.

Gullette, M. M. 1998. "Midlife Discourses in the Twentieth-Century United States: An essay on the Sexuality, Ideology, and Politics of 'Middle-Ageism"'. pp. 3-44 in Welcome to Middle Age (and Other Cultural Fictions), edited by R. A. Schweder. Chicago and London: The University of Chicago Press.

Hollway, W. 1984. “Women's Power in Heterosexual Sex". Women's Studies International Forum 7 (1): 63-68. 
Jackson, S. 1987. "Facts of Life or the Eroticization of Women's Oppression? Sexology and the Social Construction of Heterosexuality". Pp. 52-81 in The Cultural Construction of Sexuality, edited by P. Caplan. London: Tavistock.

Jackson, S. 2003. "Heterosexuality, Heteronormativity and Gender Hierarchy: Some Reflections on Recent Debates". Pp. 69-83 in Sexualities and Society: A Reader, edited by J. Weeks, J. Holland, and M. Waites. Cambridge, Oxford: Polity.

Jones, R. L. 2002. “'That's Very Rude, I shouldn't be Telling you That': Older Women Talking about Sex". Narrative Inquiry 12 (1): 121-143.

Katz, S., and B. Marshall. 2003. "New Sex for Old: Lifestyle, Consumerism and the Ethics of Aging Well”. Journal of Aging Studies 17(1): 3-16.

Marshall, B. 2002. “'Hard Science': Gendered Constructions of Sexual Dysfunction in the "Viagra Age"'. Sexualities 5 (2): 131-158.

Marshall, B., and S. Katz. 2002. "Forever Functional: Sexual Fitness and the Aging Male Body". Body \& Society 8 (4): 43-70.

Matthias R., J. Lubben, K. Atchison, and S. Schweitzer. 1997. "Sexual Activity and Satisfaction among very Old Adults: Results from a Community-Dwelling Medicare Population Survey". The Gerontologist 37 (1): 6-14.

Nicolson, P., and J. Burr. 2003. "What is 'Normal' about Women's (Hetero)sexual Desire and Orgasm? A Report of an In-depth Interview Study". Social Science and Medicine 57: 1735-1745.

Potts, A. 2002. The Science/Fiction of Sex: Feminist Deconstruction and the Vocabularies of Heterosex. London and New York: Routledge.

Potts, A. 2004. "Deleuze on Viagra (or what can a 'Viagra-body' do?)". Body and Society 10 (1): 17-36.

Potts, A., V. M. Grace, T. Vares, and N. Gavey (2006) "“Sex for Life'?: Men's Counter-Rhetoric on 'Erectile Dysfunction', Male Sexuality and Aging”. Sociology of Health and Illness 28 (3): 306-329.

Potts, A., N. Gavey, V. M. Grace, and T. Vares. 2003. "The downside of Viagra: Women's experiences and concerns”. Sociology of Health and Illness 25 (7): 697-719.

Roughan, P., F. Kaiser, and J. Morley. 1993. "Sexuality and the Older Woman", Clinics in Geriatric Medicine 9 (1): 87-106. 
Segal, L. 1994. Straight Sex: The Politics of Pleasure. London: Virago.

Segal, L. 1997. "Feminist Sexual Politics and the Heterosexual Predicament". Pp. 7789 in New Sexual Agendas, edited by L. Segal. London: Macmillan.

Smart, C. 1996. "Desperately Seeking Post-heterosexual Women”. Pp. 222-241 in Sex, Sensibility and the Gendered Body, edited by J. Holland and L. Adkins. London: Macmillan.

Tiefer, L. 1995. Sex is not a Natural Act and Other Essays. Boulder: Westview.

Twigg, J. 2004. "The Body, Gender and Age: Feminist Insights in Social Gerontology”. Journal of Aging Studies 18: 9-73. 